\title{
Perception of medical students for utility of mobile technology use in medical education
}

\section{Thakre Sushama Subhash, Thakre Subhash Bapurao ${ }^{1}$}

Department of comunity Medicine, and Coordinator, Medical

Education Technology Unit, Indira Gandhi Government Medica

College, ${ }^{1}$ Department of comunity Medicine, Government Medical College and Hospital, Nagpur, Maharashtra, India

Address for the Correspondence: Dr. Thakre Sushama Subhash, Medical Education Technology Unit, Indira Gandhi Government Medical College, Nagpur, Maharashtra, India. E-mail: sushamathakre@ rediffmail.com

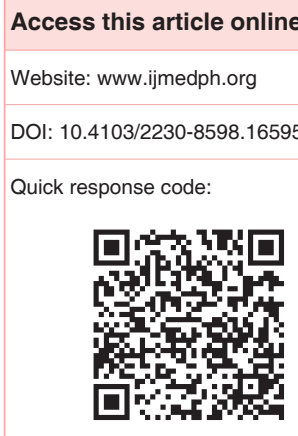

Introduction: Mobile technology is changing the way we live, and it is beginning to change the way we learn. Current literature reviews have shown that research on mobile technology in medical education primarily focused on efficacy, of mobile devices as an educational tool and resource, infrastructure to support m-learning, benefits, challenges, and appropriate use. Objectives: To assess the perception of medical student for the utility of mobile technology in their learning experience and to find out different barriers in the application of mobile phone in medical education. Materials and Methods: The study was designed as a descriptive study to assess emerging patterns of mobile technology use by medical students across the academic year 2013-2014. Interview and focus group discussion was a method of data collection. Results: Mean age \pm standard deviation of the current mobile was $3.45 \pm 1.45$ years. Mobile users were 302 (96.79\%) and Smartphone users were $261(83.61 \%)$. In the present study, $176(56.41 \%)$ used for the academic purpose and $65(20.83 \%)$ of the students preferred the same for an entertainment purpose. Gender-wise significant difference was observed in regards to Smartphone availability and daily Internet use for education purpose by female was more than male. Conclusion: The lessons learned from this study are-majority of the students use Smartphone mainly for communication, learning, and entertainment purpose. With increasing use of portable devices by students, it is logical to expect the next step to incorporate these devices in the learning environment and should, therefore, be appropriately considered for curriculum.

Key words: Learning, medical students, mobile technology, perception

\section{INTRODUCTION}

Mobile technology is changing the way we live, and it is beginning to change the way we learn ${ }^{[1]}$ Recent study indicated the frequent use of mobile devices as reference and information management tools in clinical practice and medical training among faculty, students, and residents, with a trend toward higher use among newer professionals and trainees. ${ }^{[2]}$ M-learning or mobile learning is defined as "learning across multiple contexts, through social and content interactions, using personal electronic devices." ${ }^{[3]} \mathrm{A}$ form of e-learning distance education, $\mathrm{m}$-learners can use mobile device for educational technology in many locations at their time convenience. ${ }^{[4]}$ Several studies have indicated that mobile, wireless device technology supports teaching and learning. ${ }^{[5,6]}$ An increasing number of physicians, residents, and medical students currently use mobile devices such as Smartphones, iPads, and Tablets for education and use in clinical environments. ${ }^{[7,8]}$ Medical students need to assimilate considerable new information during their studies especially with the need for evidence-based practice, and they must develop skills for lifelong learning, keeping their knowledge updated. ${ }^{[9]}$ Lifelong learning, particularly in medicine, requires motivation and problem identification and solving skills relevant to the clinical situation. ${ }^{[10]}$

This is an open access article distributed under the terms of the Creative Commons AttributionNonCommercial-ShareAlike 3.0 License, which allows others to remix, tweak, and build upon the work non-commercially, as long as the author is credited and the new creations are licensed under the identical terms.

For reprints contact: reprints@medknow.com

How to cite this article: Thakre SS, Thakre SB. Perception of medical students for utility of mobile technology use in medical education. Int J Med Public Health 2015;5:305-11. 
Current literature reviews have shown that research on mobile technology in medical education, and in health professional education in general, primarily focus on efficacy of mobile devices as an educational tool and resource, infrastructure to support $\mathrm{m}$-learning, benefits, challenges, and appropriate use. ${ }^{[2,11-15]}$ In our set up, the situation may be same or different in terms of accessibility and application of M-technology for learning at undergraduate level. The majority of students belongs to diverse socioeconomic status; variability in perception about the use of mobile and in Government Institution M-technology accessibility may find different barriers for the use of mobile in learning process.

With this background, the present study was carried out to assess the perception of medical student for the utility of mobile technology in their learning experience and to find out different barriers in the application of mobile phone in medical education. It was also planned to identify common mobile applications and extent of used by medical undergraduate students.

\section{MATERIALS AND METHODS}

In the present cross-sectional study, a representative sample of 450 medical students was selected which comprised of first $(n=150)$, second $(n=100)$, and third $(n=200)$ year students at the Indira Gandhi Government Medical College (IGGMC), Nagpur. Before conducting the study, ethical approval for the study was given by the Institutional Ethics Committee of IGGMC. The students were invited to participate in the study and informed about objectives and anonymity of the study information at one of the lectures in different subjects. All participants were provided with written information about the study and consent for participation before start of the study. They were informed that this study was completely voluntary, and they can withdraw from the study or stop participating at any time.

\section{Sample size and study design}

The minimum sample size was calculated to be 300 , taking into consideration that $40 \%$ of the student population of a previous study had self-reported an addiction to mobile phones Subba et al. ${ }^{[16]}$ with an allowable error of $10 \%$ and a $95 \%$ confidence level.

The study was designed as a descriptive study to assess emerging patterns of mobile technology use by medical students across the academic year 2013-2014. The questionnaire used for this study was designed and pretested before its use in the present study. For this purpose, piloting was done on 10 subjects, so that validity and reliability of each item were ensured. Entire process of validation was done by three independent experts in questionnaire research and descriptive study. After necessary changes in the study tool, final draft was approved and adopted for the present study.

It was a baseline survey to seek reliable information on medical undergraduates' behaviors, preference, and constraints with mobile technology in medical education learning processes. This survey consisted with 20 questions and final open-ended general question.
The adopted short survey used in this study was distributed to approximately 70-80 first, second, and final year medical students of study institution during the months of August to October of 2014. The 20-item survey questionnaire covered three main topics: Student use of mobile devices, student interest in mobile technologies as they apply to education, and technology issues related to implementing the mobile application in education.

\section{Data collection and analysis}

A direct quantitative survey was used to gather data. The survey included several closed-ended question and last open-ended sections that were further analyzed by Microsoft Excel software to illustrate discussions of the quantitative data. Descriptive statistics was used to determine mean and percentages. Continuous data were analyzed by ANOVA to derive significance. Categorical data were analyzed by use of Chi-square test. Response to open-ended question was qualitatively analyzed. This data were collected to learn more about the emerging patterns in mobile education as reported by students. Author independently identified themes to the responses, and the most common threads were reported.

\section{RESULTS}

During 2010-2013, 450 students were enrolled for the MBBS course. There were 150 students in first and 100 in $2^{\text {nd }}$ years. However; in the final year, there were 200 students. More than 356 students of similar proportions from each year voluntarily participated in the study. Hence, the response rate was $79.1 \%$. Forty-four students failed to complete study questionnaire hence were excluded from the final analysis. Survey data of 312 subjects provided information on sociodemographic characteristics, current status of mobile, applications of mobile technology, barriers, and student interest in mobile technologies as they apply to education.

Table 1 shows that of 312 students; 138 (44.33\%) and 174 (55.77\%) were male and female, respectively. It also reveals that mean age \pm standard deviation (SD) of the student participants was $20.5 \pm$ 1.73 years.

However, median age was 20 years. Eighty-nine (28.53\%) $1^{\text {st }}$ year, 82 $(26.28 \%)$ second and $151(48.40 \%) 3^{\text {rd }}$ year students had participated in the study. Majority, 265 (84.94\%) had urban residency and 47 $(15.06 \%)$ had rural residency before admission to MBBS course.

In Table 2, data analysis indicated that almost all students of first, second, and final MBBS had any one of the type of mobile. The data also showed that $89(100 \%) 1^{\text {st }}$ year students had a Smartphone or similar device. However, 78 (95.12\%) and 99 (70.21\%) of second and final MBBS students, respectively, owned a Smartphone or similar device. Mean age \pm SD of the current mobile was $3.45 \pm$ 1.45 years. Of 312 students; Smartphone users were 261 (86.42\%). Preference for the use of information technology in courses: Overall, participants indicated their preference for incorporating informational technology in education. Students' primary uses of mobile devices were assessed by self-reporting. In the present 


\begin{tabular}{lc}
\multicolumn{2}{l}{ Table 1: Sociodemographic characteristics of } \\
study participants $(\boldsymbol{n = 3 1 2})$ \\
\hline Characteristics & $\boldsymbol{n}(\%)$ \\
\hline Gender & $138(44.23)$ \\
Male & $174(55.77)$ \\
Female & \\
Age in years & $18(5.77)$ \\
17 & $43(13.78)$ \\
18 & $68(21.79)$ \\
19 & $47(15.06)$ \\
20 & $45(14.42)$ \\
21 & $71(22.76)$ \\
22 & $20(6.41)$ \\
$\geq 23$ & \\
Education in year & $89(28.53)$ \\
First MBBS & $82(26.28)$ \\
Second MBBS & $151(48.40)$ \\
Third MBBS & \\
Residence & $47(15.06)$ \\
Rural & $265(84.94)$ \\
Urban &
\end{tabular}

study, approximately 239 (76.60\%) of students preferred the use of mobile technology extensively for social purpose, $176(56.41 \%)$ use for academic purpose/the courses, and $65(20.83 \%)$ of the student preferred for an entertainment. The majority of students $180(58 \%)$ reported that they were not currently using their mobile devices to access medical resource applications. However, when asked if they would use their devices to see more use of social networking websites in their mobile-related to MBBS course, over 141 (45.19\%) of students reported that they would use their mobile devices as a study device. Table 2 shows that majority, 294 (94.87\%) students used internet on their own or others mobile. Frequency of internet use was 175 (56.09\%) daily, weekly 88 (28.20\%), and monthly 31 (9.93\%).

Table 3 shows barriers to using mobile technology in education: Students identified certain technology issues concerning the use of mobile technology in education that should be addressed to make smaller mobile devices popular for educational use. Table 3 shows that the majority 181 (58\%) of students indicated that they would prefer to have larger displays, which provide for better readability and viewing of learning materials. In addition, the time constraint was also a major $(44.87 \%)$ barrier in proportionately higher study subjects. The other factors that students identified as barriers for successful implementation of mobile technology in education were connectivity $67(21.47 \%)$, price of application 57 (18.27\%), and ignorance $19(6.09 \%)$.

Majority 178 (57.05\%) of the students use some restriction and $73(23.40 \%)$ use lot of restriction while accessing Internet.

Table 4 shows that; when asked about collaboration or working with other students using any of the following web-based tools for the educational purpose, majority of the students used video-sharing websites 153 (49.04\%), social networking websites 139 (44.55\%), Wikis (Wikipedia, course wiki, etc.) 108 (34.61\%), and web-based

\begin{tabular}{|c|c|}
\hline Characteristics & $n(\%)$ \\
\hline \multicolumn{2}{|l|}{ Mobile } \\
\hline Yes & 302 (96.79) \\
\hline No & $10(3.21)$ \\
\hline \multicolumn{2}{|l|}{ Age of current mobile in years } \\
\hline 1 & $112(35.90)$ \\
\hline 2 & $67(21.47)$ \\
\hline 3 & $55(17.63)$ \\
\hline 4 & $49(15.71)$ \\
\hline$>5$ & $29(9.29)$ \\
\hline \multicolumn{2}{|l|}{ Smartphone/android $(n=302)$} \\
\hline Yes & $261(86.42)$ \\
\hline No & $51(16.35)$ \\
\hline \multicolumn{2}{|l|}{ Internet frequency } \\
\hline Never & $18(5.77)$ \\
\hline Monthly & $31(9.94)$ \\
\hline Weekly some time & $23(7.37)$ \\
\hline Weekly several times & $65(20.83)$ \\
\hline Daily & $175(56.09)$ \\
\hline \multicolumn{2}{|l|}{ Activity performance from mobile } \\
\hline Social & $239(76.60)$ \\
\hline Academic & $176(56.41)$ \\
\hline Entertainment & $65(20.83)$ \\
\hline \multicolumn{2}{|l|}{ Purpose of social networking ${ }^{\#}$} \\
\hline Messages & $107(34.29)$ \\
\hline Email & $158(50.64)$ \\
\hline WhatsApp & $236(75.64)$ \\
\hline Facebook & $206(66.03)$ \\
\hline Linkedln & $152(48.72)$ \\
\hline Check information & $27(8.65)$ \\
\hline Others & $44(14.10)$ \\
\hline \multicolumn{2}{|l|}{ Academic use } \\
\hline Communication about patient & $33(10.58)$ \\
\hline Literature sharing (presentation, notes) & $45(14.42)$ \\
\hline Academic schedule & $97(31.09)$ \\
\hline
\end{tabular}

"Multiple responses

\section{Table 3: Barriers in mobile use}

\begin{tabular}{lc}
\hline Characteristics & $\boldsymbol{n}(\%)$ \\
\hline Barriers & $181(58.00)$ \\
Small screen & $140(44.87)$ \\
Lack of time & $67(21.47)$ \\
Lack of institutional support & $57(18.27)$ \\
lack of money & $33(10.58)$ \\
Everything is available in text book & $29(9.29)$ \\
Lack of interest & $19(6.09)$ \\
Ignorance & \\
Limit or restrict access & $28(8.97)$ \\
Do not restrict & $178(57.05)$ \\
Some restriction & $73(23.40)$ \\
Lot of restriction & $23(7.37)$ \\
Do not know & \\
\hline
\end{tabular}

word processor, spreadsheet, and presentation (GoogleDocs, iWork, Microsoft Office, Live Workspace, etc.) 94 (30.13\%). 
Table 5 shows that Smartphone mobile use was significantly $(P=0.0004)$ more in female $(n=155,89.08 \%)$ as compared to male $(n=102,73.91 \%)$. Similarly, daily Internet users were significantly $P=0.0087)$ more in females $(n=108,62.07 \%)$ as compared to male $(n=67,48.55 \%)$. For other characteristics, no significant difference was found in male verses female students.

Qualitative analysis of comments about open-ended question suggested that the majority of students perceived the use of mobile technology in medical education as a feasible application. Comments highlighted three common themes:

1. The current use of mobile technology in the academics, social communication, and entertainment.

2. Accessibility to learning materials.

3. Constraints while using mobile technology.

"I am using mobile for academic activity like presentation sharing,

\begin{tabular}{|c|c|}
\hline Characteristics & $n(\%)$ \\
\hline \multicolumn{2}{|l|}{ Application of software programs } \\
\hline Video-sharing websites (YouTube, etc.) & $153(49.04)$ \\
\hline $\begin{array}{l}\text { Social networking websites (Facebook, MySpace, } \\
\text { Bebo, Linkedln) }\end{array}$ & $139(44.55)$ \\
\hline Wikis (Wikipedia, course wiki, etc.) & $108(34.62)$ \\
\hline $\begin{array}{l}\text { Web-based word processor, spreadsheet, } \\
\text { presentation, and form applications (Google Docs, } \\
\text { iWork, Microsoft Office Live Workspace, Zoho, etc.) }\end{array}$ & $94(30.13)$ \\
\hline Photo-sharing websites (Flickr, Snapfish, Picasa, etc.) & $67(21.47)$ \\
\hline $\begin{array}{l}\text { Web-based citation/bibliography tools (CiteULike, } \\
\text { OttoBib, etc.) }\end{array}$ & $17(5.45)$ \\
\hline $\begin{array}{l}\text { Textbook publisher resource websites (Pearson, } \\
\text { Prentice Hall, McGraw) }\end{array}$ & $50(16.03)$ \\
\hline $\begin{array}{l}\text { Social bookmarking/tagging (Delicious, Digg, } \\
\text { Newsvine, Twine, etc.) }\end{array}$ & $42(13.46)$ \\
\hline Blogs & $27(8.65)$ \\
\hline $\begin{array}{l}\text { Web-based citation/bibliography tools (CiteULike, } \\
\text { OttoBib, etc.) }\end{array}$ & $17(5.45)$ \\
\hline
\end{tabular}

learning any topic in depth, but this is a supplementary because most of the things are being told during lecture or available in the textbooks" (2 $2^{\text {nd }}$ year student).

I find mobile device more useful for downloading and understanding diagram, videos, and different clinical conditions, so it is very helpful in the learning process" (final year student).

However, a small percentage of students perceived that mobile technology is best used "in the room or after the teaching schedule." However; implementation of mobile technology in education may not be cost-effective, particularly for students due to the expense of network connection and monthly charges and no institutional support.

"Most of us have advanced mobile device, but hardly we use it for academic purpose due to small screen, no knowledge about applications, lack of culture, but found very effective in communication and partly for entertainment" (first year student).

"Majority of the student expressed that very useful, helpful, and good for academic purpose" (final year student).

\section{DISCUSSION}

In the present study, students' perception indicated that all students of first, $95 \%$ of second, and $70.20 \%$ students of final M.B.B.S. had smart/android mobile phone. Overall mean age $( \pm S D)$ of mobile was 3.44 ( \pm 1.45$)$ years. However; final year students mean age $( \pm$ SD) of mobile was $3.96( \pm 1.45)$ years. Lower proportion of Smartphone by final year students could be because of the higher mean age of mobile. Smartphone technology is newer technology and at the time of introduction cost was also high hence final year student had lower proportion of Smartphone. As technology becomes older, the cost decreases and demands of new application increases hence almost $1^{\text {st }}$ and $2^{\text {nd }}$ year students had Smartphone. In the present study, $10(3.21 \%)$ of the student did not use mobile. In an earlier study, it was reported that mobile was not used by $0.68 \%$

\begin{tabular}{|c|c|c|c|}
\hline Variables & $\begin{array}{c}\text { Male }(n=138) \\
n(\%)\end{array}$ & $\begin{array}{c}\text { Female }(n=174) \\
n(\%)\end{array}$ & $P$ \\
\hline Age of study participant (mean $\pm S D$ ) years & $20.5 \pm 1.72$ & $20.12 \pm 1.71$ & $0.9426^{£}$ \\
\hline Age of the mobile (mean \pm SD) & $3.49 \pm 1.46$ & $3.41 \pm 1.44$ & $0.8647^{£}$ \\
\hline \multicolumn{4}{|l|}{ Residence } \\
\hline Urban & $119(86.23)$ & $147(84.48)$ & \multirow{2}{*}{$\begin{array}{c}X^{2}=0.3248 \\
0.5759^{\#}\end{array}$} \\
\hline Rural & $19(13.77)$ & $27(15.52)$ & \\
\hline \multicolumn{4}{|l|}{ Smartphone } \\
\hline Yes & $102(73.91)$ & $155(89.08)$ & \multirow{2}{*}{$\begin{array}{c}X^{2}=12.19 \\
0.0004^{\#}\end{array}$} \\
\hline No & $36(26.09)$ & 19 (10.92) & \\
\hline \multicolumn{4}{|l|}{ Internet use } \\
\hline Daily & $67(48.55)$ & $108(62.07)$ & \multirow{2}{*}{$\begin{array}{l}X^{2}=5.69 \\
0.0087^{\#}\end{array}$} \\
\hline Weekly/monthly & $71(51.45)$ & $66(37.93)$ & \\
\hline \multicolumn{4}{|l|}{ Use of mobile for academic activity } \\
\hline Yes & $76(55.07)$ & $104(62.07)$ & $x^{2}=0.4969$ \\
\hline No & $62(44.93)$ & $70(37.93)$ & $0.4801^{\#}$ \\
\hline
\end{tabular}

${ }^{\#}$ Chi-square test, ${ }^{\text {AANOVA }, ~} P<0.05$ considered as significant. SD $=$ Standard deviation 
of the medical students. ${ }^{[13]}$ Mobile device ownership reported in the present survey was consistent with previously reported trends in mobile ownership. ${ }^{[12,14]}$ While the previous study has also explored a single institution, ${ }^{[15]}$ a limited user group-residents or medical students and junior doctors ${ }^{[12]}$ data on mobile device use in medicine.

Students' primary uses of mobile devices were assessed by selfreporting. In spite of relatively new mobile technology; in the present study, approximately three-fourth of students preferred the use of mobile technology extensively for social communication, and more than $50 \%$ used for academic purpose.

In earlier study, students responses indicated that mobile devices were potential avenues for reviewing instructional materials, an invaluable resource for immediate feedback, and other educational purposes. ${ }^{[17]}$ Recent study reveals that physicians and medical students make decisions about using their Smartphones according to some combination of three considerations: Degree of relevance to patient care, the appropriateness of the behavior in front of patients, and the issue of how disruptive that behavior may be. ${ }^{[18]}$

There is a perceived risk that portable devices may distract from the provision of patient or client care if used by health professionals or students during employment. ${ }^{[19]}$

The present study mobile technology was extensively used for social communication. As regards to the people with whom the students communicated the most with their mobiles, a majority of them were found to do so with their parents. The reason for this in our study could be that $30 \%$ of the students in study institution were from other parts of the states and equal proportions were from different parts of Maharashtra. Their parents found it easier to keep in contact with their wards through mobile phones. This was similar to the findings of a study which was done among Malaysian college students, where $51 \%$ of the students said that they talked most often to either parent. ${ }^{[20]}$

In the present study, majority of the students used educational video-sharing websites 153 (49.04\%) and social networking websites. Nearly, one-half 139 (44.55\%) of the students used Wikis, and onethird of the students used a web-based word processor, spreadsheet, and presentation.

More than 50\% students were using internet mobile on daily, onefourth used weekly, and one tenth occasionally. Burff et al. ${ }^{[12]}$ reported that $59.1 \%$ of medical students in their clinical clerkship $\left(3^{\text {rd }}-\right.$ or $4^{\text {th }}$ year undergraduates) used them more than once a day, while $94.6 \%$ used them at least several times per week or more.

E-learning in healthcare professional education still seems like it is a new innovation, but the reality is that e-learning has been around for as long as the internet has been around. In a recent study, it has been mentioned that e-learning will also become more adaptive in the future, and so will deliver educational content based on learners' exact needs. ${ }^{[21]}$ Availability and accessibility of mobile technology perceived very positively by medical students as an educational tool. No doubt, it requires some more inputs in the form trained facilitators, other resources like connectivity and administrative support from the institution.

\section{Barriers}

The majority 181 (58\%) of students indicated that they would prefer to have larger displays, which provide for better readability and viewing of learning materials. In addition, the time constraint was also a major (44.87\%) barrier in proportionately higher study subjects. The other factors that students identified as barriers for successful implementation of mobile technology in education were connectivity $67(21.47 \%)$, and ignorance 19 (6.09\%). However; the financial barrier was expressed by 57 (18.27\%), the major concern expressed by study participants. Financial constraint was a major concern have also been reported by Zhang et al. ${ }^{[22]}$ In spite of this, it was reported that a cumulative total of $51.7 \%$ perceived that the mobile app to augment undergraduate education is helpful.

From the available literature, it reveals that since past 3 years have seen an increase in the literature reporting the successful utility of mobile technology in higher education. ${ }^{[2,11,13-16]}$ In the earlier study by Boruff $\mathrm{f}^{12]}$ reported that "knowing what resources were available" (55.8\%) and "lack of time" (26.3\%) were the other most commonly reported barriers to access, among all groups. Other barriers included "understanding how to use the resources" (20.8\%), "technology problems" (20.7\%), or "complicated installation process" (18.3\%).

In the present study, one-fifth of the study subjects were using mobile as a media for entertainment. In an earlier study, ${ }^{[23]}$ the vast majority of young people now carry devices on which they play games, listen to music, and in many cases, connect to the Internet and watch videos. ${ }^{[23]}$

In the present study, majority of the students expressed inability to use mobile as an educational tool. It also reveal that lack of institutional support like no Wi-Fi facility in the campus, financial constraints, and lack of time were the major barriers in the application of mobile in medical education. Moreover, results from this present study reflected prior needs assessment reports with regard to two separate issues: Student availability of mobile technology and inclination of a medical student to use this technology in medical education. Mobile application and technology issues should be addressed by each institution in order to successfully incorporate mobile technology in education, particularly with regard to resources in terms of computer technology, institutional technology infrastructure, faculty awareness of efficient application of mobile devices for content delivery, and student accessibility. ${ }^{[19]}$ Literature also suggests that availability and accessibility of technology is one issue and another important issue is that faculty is integrated with the process. They have the training and resources to feel properly supported and that they understand this is where education is going. ${ }^{[2]}$

Mobile technology in medical education has to make sure that 
faculty is integrated into the process that they understand this is where education is going, and that they have the training and resources to feel properly supported. ${ }^{[17]}$ Nevertheless, students are using mobile technology such as Smartphone/android because they provide on demand accessibility to information regardless of whether faculty will incorporate such technology in their teaching.

\section{Limitation of the study}

This study is limited by the personal reporting of voluntary respondents. A possible inherent issue in their responses is bias related to prior experiences with technology. Findings of the study cannot be generalized to entire medical student population as data were generated from the single institution. Extent of use of mobile technology was not quantified in this study.

\section{CONCLUSION AND RECOMMENDATIONS}

The lessons learned from this study are majority of the student uses Smartphone for communication, learning, and entertainment. Positive inclination and perception is a good sign for m-learning in medical education. Availability and acceptability of mobile in the learning process is a great asset. Most important barriers for not use of technology were lack of time, knowledge, etc., which need to be addressed in proper perspectives. Understanding the opportunities and challenges of using mobile devices in the academic medical environment can help to determine the inclination and perceptions of their Smartphone use. Undergraduate medical students are well versed with the use of You Tube and word processor document sharing used for learning. It also concludes that significantly more female students use Smartphone and internet facility as compared to boys. The strength of this study is that the medical undergraduate's student participants are from one institution. Hence, uniformity is ensured. With increasing use of portable devices by students, it is logical to expect the next step to incorporate these devices in the learning environment and should be consider for curriculum.

\section{Acknowledgment}

I express special thanks to my guide Dr. Tripti Shrivastava, Professor in Physiology, MCI Nodal Centre for National Faculty development, JNMC, Sawangi (M), Datta Meghe Institute of Medical Sciences (Deemed University), Wardha, Wardha for her untiring effort, support, and guidance to bring this study in final shape.

I would like to take this opportunity to express my sincere gratitude to all those who have in some way contributed to bring this study in the final shape. In particular, we would like to thank the undergraduate medical students of IGGMC, Nagpur, who participated in this study with all enthusiasm. Special gratitude goes to Dr. Sunita Vagha, Coordinator of MET Unit of MCI Nodal Centre for National Faculty development, JNMC, Sawangi (M), Datta Meghe Institute of Medical Sciences (Deemed University), Wardha, for her constant support.

I must express special thanks to Dr. Sachin Hiware, Assistant Professor in Pharmacology, IGGMC, Nagpur, for his valuable contribution in validation of study tool and items.

We hope this study will serve the purpose of informing the strategies and actions for any concerned stakeholders in improving the mobile technology in medical education.

\section{Financial support and sponsorship}

Nil.

\section{Conflicts of interest}

There are no conflicts of interest.

\section{REFERENCES}

1. ICT in Education. Available from: http://www.unesco.org/new/en/unesco/ themes/icts/m4ed/uary. [Last accessed on 2014 Jan 09].

2. Wallace S, Clark M, White J. 'It's on my iPhone': Attitudes to the use of mobile computing devices in medical education, a mixed-methods study. BMJ Open 2012;2:doi: 10.1136/bmjopen-2012-001099.

3. Crompton H. A historical overview of mobile learning: Toward learnercentered education. In: Berge ZL, Muilenburg LY, editors. Handbook of Mobile Learning. Florence, KY: Routledge; 2013. p. 3-14.

4. Louise M, Lee D. Critical issues of m-learning: Design models, adoption processes, and future trends. J Chin Inst Ind Eng 2011;28:111-23.

5. Dearnley C, Haigh J, Fairhall J. Using mobile technologies for assessment and learning in practice settings: A case study. Nurse Educ Pract 2008;8:197-204.

6. Mayfield CH, Ohara PT, O'Sullivan PS. Perceptions of a mobile technology on learning strategies in the anatomy laboratory. Anat Sci Educ 2013;6:819.

7. Davies BS, Rafique J, Vincent TR, Fairclough J, Packer MH, Vincent R, et al. Mobile how mobile information resources contribute to learning for undergraduate clinical students - A mixed methods study. BMC Med Educ 2012;12:1.

8. Pimmer C, Linxen S, Gröhbiel U, Jha AK, Burg G. Mobile learning in resource-constrained environments: A case study of medical education. Med Teach 2013;35:e1157-65.

9. General Medical Council. Tomorrow's doctors: Recommendations on undergraduate medical education. London: General Medical Council; 2009.

10. Holzinger A, Nischelwitzer A, Meisenberger M. Lifelong-learning Support by $\mathrm{m}$-Learning; Example Scenarios. Available from: http://www.elearnmag. acm.org/archive.cfm?aid=1125284. [Last accessed on 2015 Feb 12].

11. Chu LF, Erlendson MJ, Sun JS, Alva HL, Clemenson AM. Mobile computing in medical education: Opportunities and challenges. Curr Opin Anaesthesiol 2012;25:699-718.

12. Boruff JT, Storie D. Mobile devices in medicine: A survey of how medical students, residents, and faculty use smartphones and other mobile devices to find information. J Med Libr Assoc 2014;102:22-30.

13. Anuj M, Rajasekar VD, Krishnagopal L. A study to assess economic burden and practice of cell phone disposal among medical students. J Clin Diagn Res 2013;7:657-60.

14. Payne KB, Wharrad $H$, Watts K. Smartphone and medical related App use among medical students and junior doctors in the United Kingdom (UK): A regional survey. BMC Med Inform Decis Mak 2012; 12:121.

15. Chatterley T, Chojecki D. Personal digital assistant usage among undergraduate medical students: Exploring trends, barriers, and the advent of smartphones. J Med Libr Assoc 2010;98:157-60.

16. Subba SH, Mandelia C, Pathak V, Reddy D, Goel A, Tayal A, et al. Ringxiety and the mobile phone usage pattern among the students of a medical college in South India. J Clin Diagn Res 2013; 7:205-9.

17. Vafa S, Chico DE. A needs assessment for mobile technology use in medical education. Int J Med Educ 2013;4:230-5.

18. Johnson AC, El Hajj SC, Perret JN, Caffery TS, Jones GN, Musso MW. Smartphones in medicine: Emerging practices in an academic medical center. J Med Syst 2015;39:164. 
19. Mather C, Cummings E, Allen P. Nurses' use of mobile devices to access information in health care environments in Australia: A survey of undergraduate students. JMIR Mhealth Uhealth 2014;2:e56.

20. Zulkefly SN, Baharudin R. Mobile phone use amongst students in a university in Malaysia: Its correlates and relationship to psychological health. Eur J Sci Res 2009;37:206-18.

21. Walsh K. The future of e-learning in healthcare professional education: Some possible directions. Commentary. Ann Ist Super Sanita 2014; 50:309-10.

22. Zhang M, Cheow E, Ho CS, Ng BY, Ho R, Cheok CC. Application of low- cost methodologies for mobile phone app development. JMIR Mhealth Uhealth 2014;2:e55.

23. Kaiser Family Foundation Study. Available from: http://www. kaiserfamilyfoundation.files.wordpress.com/2013/01/8010.pdf Last access on 2015 Jan 9.

24. Fuhrman T. Making the iPad the Center of the Academic Experience. Campus Technology. Available from: http://www.camp ustechnology. com/articles/2013/02/14/making-the-ipad-the-center-of-theacademicexperience.aspx. [Last cited on 2015 Jan 09]. 